\title{
Processos de inserção de analfabetos e semi-alfabetizados no mundo da cultura escrita (1930-1950)
}

\section{Ana Maria de Oliveira Galvão}

Faculdade de Educação, U niverisdade Federal de Pernambuco

\section{Introdução}

Os estudos que investigam a aquisição da leitura e da escrita e os usos que são feitos dessas habilidades nas sociedades contemporâneas enfatizam o papel central desempenhado pela escola nesses processos. Se essa centralidade pode ser questionada mesmo quando se fala nas sociedades atuais (na medida em que não se pode falar em uma única "contemporaneidade", particularmente no caso brasileiro), merece ser posta em reflexão, ainda com mais ênfase, quando se fala do passado. Mas, mesmo no Brasil, grande parte dos estudos realizados na área de história da educação tem considerado, predominantemente, a escola como o espaço educativo por excelência. Por vezes, tem-se a impressão de que, entre as camadas analfabetas ou semi-alfabetizadas, a única mediação entre a leitura e a escrita é realizada pela escola. No entanto, práticas educativas têm ocorrido, ao longo do tempo, fora da escola e, às vezes, com maior força do que se considera, principalmente para determinados grupos sociais e em determinadas épocas. ${ }^{1}$

${ }^{1}$ No período de 1992 a 1994 realizei uma pesquisa, que resultou em meu trabalho de mestrado, sobre o cotidiano da escola primária na
Algumas questões, diante desse quadro, merecem ser colocadas: como as pessoas que não tinham acesso à escola ou que tinham uma escolarização restrita se inseriam em culturas já profundamente marcadas pela presença da escrita? Em que níveis essa inserção se dava? Neste texto, tento trazer, a partir dessas questões, alguns elementos para refletir sobre o tema, de forma exploratória. Esses elementos que busco aqui explicitar advêm, principalmente, de resultados do meu trabalho de Doutorado, ${ }^{2}$ em especial de uma análise mais detida

Paraíba entre 1890 e 1920 (Galvão, 1994 e 1998). Nesse trabalho, pude verificar que no Brasil naquele momento histórico, a escola não possuía a força formativa que hoje possui, na medida em que menos de $10 \%$ da população a ela tinha acesso. Principalmente nas memórias e autobiografias que analisei, elementos educativos existentes fora da escola pareciam ter mais importância na inserção de meninos e meninas em um determinado mundo cultural do que mesmo a escola. Em minha pesquisa de doutorado, ao estudar a literatura de cordel, verifiquei que, para alguns segmentos sociais, esse tipo de literatura, tradicionalmente classificada como popular, representava um dos únicos contatos que tinham com a escrita, a leitura e o impresso.

2 A pesquisa, orientada por Magda Soares, objetivou (re)construir o público leitor, as maneiras de ler, os papéis atribuídos 
das entrevistas realizadas com nove leitores/ouvintes e vendedor de folhetos de cordel, que vivenciaram suas experiências com esse tipo de literatura no período aproximado de 1930 a 1950, em Pernambuco. De modo geral, pessoas analfabetas ou pouco escolarizadas que tiveram, em graus diferentes, contatos com impressos e deles realizaram leituras ou audições.

\section{Fatoresque parecem influenciar no processo de inserção dossujeitosna cultura escrita}

Que níveis de letramento apresentavam, então, os sujeitos que entrevistei? Tomo aqui, a palavra letramento em um sentido amplo, considerada, sobretudo, como “...o estado ou a condição que adquire um grupo social ou um indivíduo como consequiência de ter-se apropriado da escrita" (Soares, 1998, p.18). ${ }^{3}$ Permito-me dela utilizar como um instrumento para melhor compreender as diferenciações apresentadas pelos sujeitos entrevistados, que muitas vezes apresentavam entre si um grau semelhante de escolarização (noção considerada, então, insuficiente, embora não desprezível), em relação ao contato que tinham com a palavra escrita e aos usos efetivos que faziam dela. Por não ter sido o objetivo da pesquisa "medir" os níveis de letramento da população estuda-

à leitura e as formas de apropriação da leitura de folhetos de cordel, no período de 1930 a 1950, em Pernambuco (Galvão, 2000). Na reconstrução do público leitor/ouvinte e de seus modos de ler/ouvir folhetos, utilizei como principais fontes: entrevistas, autobiografias, romances, os próprios folhetos e documentos diversos escritos sobre ou no período aludido.

${ }^{3}$ Para Soares (1998), a partir desse ponto de vista, um sujeito, mesmo sendo analfabeto, pode, em alguns casos, ser considerado, de certa forma, letrado, na medida em que o mais importante, no conceito, são os usos da escrita feitos pelos sujeitos. No entanto, a autora reconhece que o fenômeno de letramento é difícil de ser definido e avaliado, na medida em que “...cobre uma vasta gama de conhecimentos, habilidades, capacidades, valores, usos e funções sociais”, envolvendo, portanto, “...sutilezas e complexidades difíceis de serem contempladas em uma única definição.” (p. 65-66). A respeito dos conceitos de letramento e alfabetismo e de suas utilizações em pesquisas no Brasil, ver, além da obra citada, Soares (1995), Ribeiro (1999) e coletânea organizada Kleiman (1995). da, o que apresento aqui são apenas algumas pistas e algumas indicações de como o conceito pode ser útil na compreensão desses processos.

Caracterizo então os sujeitos que entrevistei, todos moradores do Recife, nascidos em sua região metropolitana ou em cidades do interior de Pernambuco e da Paraíba, entre 1910 e 1932, principalmente a partir de seus níveis de escolarização e da leitura ou audição que faziam de objetos impressos.

Dos nove sujeitos que entrevistei, três declararamse analfabetos, três tiveram experiências de escolarização de até um ano e três passaram de dois a cinco anos na escola. Nas trajetórias de vida de todos eles, os folhetos constituíram o objeto de leitura e/ou audição mais presente. Para os analfabetos, leitura em voz alta sempre mediada por alguém alfabetizado: em geral, os filhos ou vizinhos e, eventualmente, o cônjuge. Os outros, na maior parte das vezes, liam os cordéis em voz alta para um grupo e, em outros momentos, realizavam uma leitura solitária, silenciosa.

Além dos folhetos, essas pessoas tinham experiências de leitura com outros objetos impressos? Dos nove entrevistados, quatro afirmaram não terem tido outras experiências de leitura/audição de impressos em suas trajetórias. Crispim, ${ }^{4}$ Ana Maria ${ }^{5}$ e Zé Mariano, ${ }^{6}$ todos analfabetos e os dois primeiros moradores de uma cidade sertaneja até recentemente, embora tenham tido contato com outros objetos de leitura, não experimentaram a sensação de ler ou ouvir notícias, histórias, descrições, poesias fora do suporte do folheto. Delita ${ }^{7}$ se alfabeti-

${ }^{4}$ Crispim, casado com Ana Maria, nasceu em Sertânia, sertão de Pernambuco, em 1910. Trabalhou, durante a maior parte da vida, como pequeno agricultor. Em 1997, quando o entrevistei, morava há dois anos no Recife.

${ }^{5}$ Ana Maria, dona-de-casa, casada com Crispim, nasceu também em Sertânia. Entrevistada em 1997.

${ }^{6}$ Zé Mariano, entrevistado em 1996 e 1997, nasceu em Umbuzeiro, Paraíba, em 1922. Trabalhou, inicialmente, como pequeno agricultor e, depois que migrou para o Recife, como pedreiro e em outras ocupações, principalmente na construção civil. Analfabeto, nunca freqüientou a escola.

${ }^{7}$ Delita, mãe de Zezé e de Zeli, nasceu em Pilar, Paraíba, em 1911. Desde os 16 anos mora em uma cidade da região metropolita- 
zou já adulta e, embora moradora do grande Recife durante a maior parte da sua vida, sua experiência de leitura/audição de impressos esteve restrita aos folhetos. Nas memórias e romances analisados, os personagens que se referem aos folhetos, salvo uma exceção, também não possuem muitas outras experiências de leitura. Ao contrário de outros leitores que, morando na mesma cidade, mas pertencentes principalmente a outros grupos sociais, experimentavam uma grande diversidade de contatos com objetos impressos.

Os outros cinco entrevistados revelaram terem tido e, em alguns casos, ainda terem, experiências de leitura com outros objetos impressos. Zé Moreno, ${ }^{8}$ Edson, ${ }^{9}$ Antônio ${ }^{10}$ e Zezé ${ }^{11}$ moraram, durante a maior parte de suas vidas, no Recife e tiveram, em alguns casos mais restritas (caso dos dois primeiros), em outros mais longas (caso dos dois últimos), experiências de escolarização. Zeli ${ }^{12}$ morou a maior parte do tempo em pequenas cidades do interior do Estado, e suas outras experiências de leitura, assim como as de Zezé, praticamente se restringiram às cartilhas e aos livros didáticos dos primeiros anos de instrução. Dois dos homens desse grupo foram os que revelaram maior intimidade com a leitura

na do Recife. Trabalhou a maior parte da vida como lavadeira. Entrevistada em 1997.

${ }^{8}$ Zé Moreno nasceu em Nazaré da Mata, zona da mata de Pernambuco, em 1924. Migrou para o Recife aos dezesseis anos. Durante a maior parte de sua vida, trabalhou como motorista de caminhão e de táxi. Estudou somente "uma parte da carta do ABC". Entrevistado, em duas ocasiões, em 1997.

${ }^{9}$ Edson nasceu em Limoeiro, agreste de Pernambuco, em 1921 Vende folhetos de cordel desde 1938. Entrevistado para esta pesquisa em 1996 e 1997.

${ }^{10}$ Antônio nasceu em Bezerros, agreste de Pernambuco, em 1925. Militar durante a maior parte de sua vida, há vários anos trabalha como ambulante no centro do Recife. Estudou até o "terceiro livro de leitura." Entrevistado em 1997.

${ }^{11}$ Zezé, filha de Delita e irmã de Zeli, nasceu em Jaboatão, na região metropolitana do Recife, em 1932. Dona-de-casa, cursou os quatro primeiros anos da escola primária. Entrevistada em 1997.

${ }^{12}$ Zeli, filha de Delita e irmã de Zezé, nasceu em Jaboatão, na região metropolitana do Recife, em 1930. Dona-de-casa, estudou até o "terceiro livro de leitura." Entrevistada em 1997. e maior diversidade de experiências com diferentes objetos impressos e não impressos. Entre os gêneros preferidos por eles, estão aqueles que, de modo geral, são considerados "populares", mas que, no Recife das décadas de 1930 e 1940, circulavam também entre as camadas mais "letradas" da população.

O que parece influenciar para que alguns sujeitos tenham apresentado contatos diferenciados e tenham feito usos diversos dos objetos que compõem o mundo da cultura escrita? ${ }^{13}$

Inicialmente, parece que a aprendizagem das habilidades básicas de leitura - a alfabetização inicial - seja por processos autodidatas, seja por processos de escolarização formal -, constitui o fator preponderante para que os sujeitos se sintam mais habituados ao mundo $l e-$ trado, fazendo dele parte significativa de sua vida. No entanto, a partir da aquisição dessas habilidades, o nível de escolarização dos sujeitos não se constitui mais, necessariamente, um fator fundamental para as suas experiências de letramento. ${ }^{14}$

Outro fator que se revelou muito significativo é o que se refere aos níveis de inserção na cultura urbana. Viver na cidade, embora originário da zona rural, imerso em um mundo onde o impresso se encontra em todos os lugares, parecia fundamental, naquele momento, para os processos gradativos de aquisição de uma maior familiaridade com a cultura escrita. ${ }^{15}$

$O$ pertencimento de gênero também pareceu decisivo para a determinação dos graus de letramento dos entrevistados. As mulheres tiveram contato com uma menor diversidade de objetos escritos e apresentaram menor intimidade com eles. ${ }^{16} \mathrm{Na}$ verdade, como se verá mais detalhadamente a seguir, os diferentes graus de

${ }^{13}$ Busquei responder a essa questão a partir da análise dos textos das entrevistas, mas também a partir das reações, dos modos de lidar com os impressos e de falar sobre eles observados nos próprios processos das entrevistas.

${ }^{14}$ Ver, para a discussão dessa questão em processos contemporâneos, o estudo de Ribeiro (1999).

${ }^{15}$ Essa questão já foi constatada em outros estudos, como, por exemplo, por Magalhães (1999), no caso português.

${ }^{16}$ Exceção a Zeli, que demonstrou grande intimidade com a literatura de folhetos. 
apropriação do espaço urbano estavam diretamente associados ao ser homem ou ser mulher na sociedade da época. Os espaços de sociabilidade femininos eram ainda restritos, mesmo no caso de mulheres pertencentes às camadas populares e engajadas no mercado de trabalho. ${ }^{17}$

Finalmente, a ocupação profissional também parecia se constituir em um fator importante para a maior ou menor intimidade das pessoas com a escrita. Sujeitos que exerceram, durante a maior parte da vida, ocupações manuais, assalariadas ou "autônomas" (de subsistência, como o trabalho no campo), ou, no caso da maior parte das mulheres, não trabalharam fora do lar, apresentaram menores níveis de letramento. Trabalhadores em ocupações semi-especializadas, em contrapartida, revelaram maior grau de inserção na cultura escrita. ${ }^{18}$

A classe social a que pertenciam os sujeitos não se constituiu em um fator fundamental na análise específica que fiz, na medida em que, de modo geral, os entrevistados pertenciam ao mesmo grupo social. No entanto, através da análise realizada a partir das autobiografias e romances, tornou-se evidente que as condições de acesso aos objetos característicos do mundo letrado e as relações estabelecidas entre as pessoas pertencentes às camadas médias e esses objetos eram muito mais naturais do que aquelas mantidas por pessoas dos segmentos populares. Mas o pertencimento social não era o único determinante nesse processo, nem talvez o principal. A evidência citada refere-se, sobretudo, às camadas médias urbanas: a inserção na cultura das cidades parecia se sobrepor, naquele momento, ao pertencimento social. Além disso, em alguns casos, os mesmos objetos de leitura circulavam entre as diferentes camadas sociais.

${ }^{17}$ Alvim (1997), em seu estudo sobre a Companhia de Tecidos Paulista, localizada em Pernambuco, nas décadas de 1930 e 1940, indica que, embora a mão-de-obra feminina compusesse um contingente significativo da empresa, ocupava funções específicas (que excluíam as atividades no exterior da fábrica) e tinha um espaço delimitado dentro da fábrica. Além disso, o trabalho fabril se inseria em uma concepção mais geral sobre o trabalho feminino: era visto como temporário e anterior ao casamento.

${ }^{18}$ Constatação também feita por Magalhães (1999), para o caso português.
Outros fatores que não apareceram na pesquisa podem também ser levantados como influentes na determinação dos níveis de letramento de certos grupos: um deles é a militância política. As atividades realizadas em movimentos sindicais (e sociais, de modo mais amplo) parecem contribuir para o desenvolvimento de habilidades consideradas típicas da cultura escrita, mesmo quando exercidas por pessoas analfabetas. ${ }^{19}$ Possivelmente, um outro fator que merece ser investigado refere-se ao pertencimento racial e/ou étnico, embora no grupo de entrevistados com que trabalhei, ainda que houvesse uma ligeira predominância de negros, esse fator não pareceu ter influência significativa nos processos de letramento dos sujeitos. Além desses fatores, poderia também fazer referência à força de processos autodidatas que marcaram, em alguns casos ligeiramente, em outros decisivamente, as trajetórias de vida de alguns sujeitos. No entanto, a complexidade de fatores envolvidos nesse processo exige estudos mais aprofundados especificamente sobre o tema. ${ }^{20}$

Assim, a experiência urbana, o pertencimento a um ou outro sexo e a aprendizagem das habilidades básicas de leitura parecem constituir fatores importantes para a diversificação das experiências de leitura. Alfabetizados; homens; com fortes experiências urbanas; trabalhadores, durante a maior parte da vida, em ocupações semi-especializadas: esse é o perfil geral dos entrevistados que tiveram uma trajetória de leitores que ultrapassou significativamente a experiência com os folhetos. Mas, principalmente para essas pessoas, como se davam, em suas trajetórias individuais, essas diferentes inserções no mundo letrado?

${ }^{19}$ Ver, a esse respeito, em processos contemporâneos, Kleiman (1995) e Ratto (1995).

${ }^{20}$ No Brasil, na área de educação e, particularmente, no campo da história da educação, são quase inexistentes os trabalhos que tematizam a questão do autodidatismo, embora se saiba que somente a partir da década de 50 do século XX, a escola comece a ocupar um papel significativo, pelo menos numericamente, na inserção das pessoas no mundo da leitura e da escrita. Em outros países, como a França, por outro lado, esse tema foi objeto de alguns trabalhos. Ver, entre outros, Hébrard (1996a, 1996b e s.d.) e o número especial da revista Histoire de l'Éducation sobre autodidaxias (Frijhoff, 1996). 


\section{Como se davam os processos de inserção na cultura escrita? Algumasaproximações}

Centro, aqui, minha exposição, na busca de reconstrução dos processos pelos quais as pessoas, tomando especificamente o grupo de sujeitos que pesquisei, foram, em menor ou maior grau, apropriando-se e inserindo-se no mundo da cultura escrita. Esses processos, embora em grande parte fluidos e imprevisíveis, dependentes de uma série de fatores constitutivos da trajetória de cada um dos leitores, podem ser, em linhas gerais, visualizados.

\section{0 acesso à alfabetização e às primeiras leituras}

Os outros objetos de leitura, além dos folhetos, mais citados pelos leitores/ouvintes que entrevistei foram as cartilhas e os livros didáticos. Referências à "Carta do ABC" aparecem nas entrevistas, nas memórias e nos romances que analisei. Parecia ser, ainda nas décadas de 1930 e 1940, largamente utilizada no Recife e em Pernambuco, de modo geral. ${ }^{21}$ Além de utilizada em processos formais $^{22} \mathrm{e}_{\text {informais }}{ }^{23}$ de ensino, é comum a re-

${ }^{21}$ Embora já criticadas no final do século XIX, as cartas do ABC ou abecedários foram amplamente utilizados no Brasil até meados do nosso século. Pfromm Neto et al. (1974) afirmam que, até o início da década de 30, a editora Globo, de Porto Alegre, anunciava suas "Cartas do ABC", folheto vendido por 200 réis, que parece, segundo os autores, ter tido sucessivas edições.

${ }^{22}$ Paulo Freire, nascido em uma época em que as Cartas do ABC eram quase obrigatórias no aprendizado da leitura e da escrita, considera sua experiência particular uma exceção: "Em lugar de uma enfadonha cartilha ou, o que seria pior, de uma 'Carta do ABC', em que as crianças tinham de decorar as letras do alfabeto, como se aprendessem a falar dizendo letras, tive o quintal mesmo de minha casa - o meu primeiro mundo - como minha primeira escola" (Freire, 1994, p. 49). Segundo o autor, uma das maiores dificuldades que enfrentou quando foi trabalhar no final da década de 1940 no SESI do Recife, foi tentar convencer os trabalhadores de que poderia haver outros caminhos, além da Carta do ABC, para a aprendizagem da leitura e da escrita. Para eles, o método havia funcionado com seus avós, pais e com eles mesmos, não havendo necessidade de mudanças.

${ }^{23}$ Era comum se aprender a ler com a Carta do ABC em casa, antes do ingresso na escola formal. ferência, nas fontes analisadas, aos processos autodidatas de alfabetização através desses impressos. Em um processo solitário de reflexão metalingüística, de construção de hipóteses, na tentativa de conferir significados para uma nova linguagem, adultos analfabetos se alfabetizavam.

João Martins de Athayde, um dos principais editores de folhetos da história do cordel, não freqüentou a escola. Foi a partir do desejo de fazer versos que o poeta aprendeu a ler, através também de uma das cartas do ABC mais utilizadas na época - a de Landelino Rocha:

$\mathrm{O}$ que aprendi de leitura foi quase por minha conta e pela minha força de vontade.Sentindo desejo de escrever as minhas glosas, comprei uma carta de ABC de Landelino Rocha e andava com ela dentro do chapéu para toda parte. Eu ia tratar do gado e me sentava, às vezes, debaixo dos pés de pau só para estudar as lições. Quando cheguei na parte que diz: 'É meu pai...'não precisei mais de ajuda de ninguém e por mim mesmo continuei a aprender. Acontece, porém, que eu aprendi a escrever com a mão esquerda e por isso minhas palavras apareciam escritas pelo avesso [...] Depois endireitei e fui pelo caminho dos outros. (apud Terra,1983, p. 45-46).

De maneira semelhante a Athayde, a partir da necessidade de saber utilizar a escrita na vida cotidiana, Gregório Bezerra (1980) aprendeu a ler. Aos 25 anos, o ex-camponês e então soldado do exército, que sempre havia desejado estudar, necessitou de escrever uma carta para a irmã. Ao ver seu pedido protelado por um colega de profissão, tomou a decisão de, sozinho, aprender a ler. Comprou uma cartilha e, com disciplina, foi aos poucos se alfabetizando: "Numa semana li e reli a cartilha muitas vezes; se uma sílaba ou palavra me atrapalhava, recorria a qualquer pessoa que soubesse ler; e assim fiz, até me convencer de que já sabia toda a cartilha" (p. 195).

Pesquisa realizada por Ribeiro (1999), na atualidade, na capital paulista, mostra que a aprendizagem inicial, autodidata, da leitura, através da carta do $\mathrm{ABC}$ ainda é uma realidade no Brasil, mesmo nos grandes centros urbanos. Um dos sujeitos entrevistados pela autora, Sebastião, revela que comprou uma carta do $\mathrm{ABC}$, consultada à medida em que se esforçava para, no condomínio em que trabalhou como porteiro, decifrar os jornais e as correspondências que distribuía. Em pro- 
cesso semelhante aos sujeitos que entrevistei, fica explícita, no depoimento de Sebastião, a necessidade constante de reflexão para, aos poucos, por meio do levantamento e confirmação de certas hipóteses, construir uma compreensão inteligível do sistema alfabético: "Com o "l" e com o "b" é que eu me atrapalhava. Que aqui você tem o "bla", sem o "l" é "ba". [...] Era complicado para você entender o porquê daquela letra ali, aí depois que eu vim me tocar, o que faz esse "l" e esse " $r$ " entre o " $b$ " e o "a", isso é o que faz o significado da língua." Diante da questão da entrevistadora, que buscava compreender como Sebastião havia entendido esse processo - por meio da fala ou da repetição -, o entrevistado afirma: "Não, pensando porquê. Depois que eu fui entendendo, lendo jornal, lendo jornal que eu fui entender" (Ribeiro, 1999, p. 177).

No estudo que realizei, em outros casos, os próprios folhetos de cordel eram um instrumento nos processos iniciais de aprendizagem da leitura. Muitos estudos (ver, por exemplo, Maxado, 1984, e Meyer, 1980) realizados sobre o tema no Brasil apontam o papel dos folhetos na alfabetização de um significativo número de pessoas, principalmente na época de seu apogeu. Entre as pessoas que entrevistei, a maioria conhecia alguém ou tinha ouvido falar sobre a aprendizagem inicial da leitura através dos cordéis.

Os depoimentos parecem indicar que era de uma maneira autodidata que as pessoas aprendiam a ler por meio dos folhetos:

Mesmo quem não sabia ler comprava e aprendia a ler lendo cordel, decorava. E terminava aprendendo a ler (risos) por causa do cordel, né? Porque decorava aquela leitura do cordel [...] Então dali ia juntando as letra, daqui a pouco sabia ler. [...] Acompanhando. O cordel é uma coisa da antigüidade que... trouxe a muita gente aprender a ler que comprava o folheto, porque queria ler também e terminava lendo. [...] Eu conheço, aqui não, no interior, né? Muita gente que aprendeu a ler por causa do cordel. (Edson).

Na mesma direção, Zeli associa a aprendizagem da leitura à audição - e também memorização - dos folhetos: "Via, ouvia, gostava e pegava e ia ler, soletrando e aprendia $[\ldots]$ muita gente aprendeu a ler com o folheto". No entanto, associa esse papel da leitura dos folhetos diretamente ao que parecia ser sua função ou sua conseqüência primeira: o lazer, o divertimento, a inserção em um mundo mágico. $\mathrm{O}$ interesse despertado pelas histórias é que determinava essa função de cunho mais pragmático da leitura: "Era, ia aprendendo, era. Com o folheto ia aprendendo a ler. Se interessava pela história, né? E ia aprendendo a ler, ia assoletrando, né? [...] Era umas histórias bonitas de rei e rainha, das fadas que transformava o povo em.. nera?". Assim, pela memorização dos poemas, lidos ou recitados por outras pessoas, o "alfabetizando", em um processo solitário de reconhecimento das palavras e versos, procedia, ele mesmo, à aprendizagem inicial da leitura.

Em outros casos, o folheto aparece como o principal motivador para que os meios formais de aprendizado da leitura e da escrita fossem procurados. De maneira semelhante a Antônio, que afirma ter se esforçado na escola para aprender a ler movido pelo desejo de poder ler folhetos sozinho, para Zé Moreno uma das principais motivações que teve para aprender a ler quando criança era a possibilidade de, ele mesmo, ler folhetos. A prática da leitura já era corrente em sua família:

Na minha época de menino, de primário, de escola, eu era doido pra ler folheto porque na minha casa eu tinha um tio meio curioso que não sabia ler, mas arranhava. Ele lia aquilo e eu ficava invejoso. E eu não sabia, me botaram na escola e eu aprendi algumas linhas e me fixei naqueles versos, naquelas coisas e sei alguma coisa...

Para a fixação das primeiras aprendizagens em relação à leitura, era também comum a utilização dos livros de leitura utilizados na seqüência das cartas do ABC. Além de utilizados nos processos formais ${ }^{24}$ de escolarização, também pareciam ser um instrumento útil nas autodidaxias. Para prosseguir em seus estudos com

${ }^{24} \mathrm{E}$ também informais, na medida em que muitos só iam para a escola após o término do Primeiro Livro de Leitura. Uma das personagens do romance Tempestade no Porão (Alves da Mota, 1987), a menina Claudina, por exemplo, só ingressa na escola após o término do primeiro livro de Felisberto de Carvalho. Assim também ocorreu com Carlinhos, personagem alter-ego de José Lins do Rego (1977), em Doidinho, no início do século na Paraíba. 
o objetivo de aprender a ler e escrever, Gregório Bezerra (1980), por exemplo, recorreu ao Primeiro Livro de Leitura de Felisberto de Carvalho, lendo-o e relendo-o várias vezes, a ponto de sabê-lo quase todo de cor. ${ }^{25}$

\section{0 desenvolvimento das competências de leitura através da inserção na cultura urbana}

\section{O espaço da rua}

Como já me referi, a inserção na cultura urbana parecia ser um fator decisivo para o desenvolvimento dos níveis de letramento da população que estudei. Mesmo para aqueles que nunca freqüentaram a escola, as experiências vividas em um espaço em que o impresso se encontrava por toda a parte trazia uma maior intimidade com o mundo da leitura e da escrita.

É muito provável, por exemplo, que, principalmente para os moradores do Recife, diversas tenham sido as vezes em que pediram para alguém ler a destinação do bonde ou ônibus de que precisavam, as placas de rua, os boletins, os manifestos políticos, os almanaques, as folhinhas, os folhetos de propaganda que recebiam... (ver, por exemplo, Rego, 1993, Alves da Mota, 1987, Varejão, 1992, Sette, 1995, Bezerra, 1980, Freyre, 1975). A cidade tinha, entre as décadas de 1930 e 1940, uma população em torno de 400 mil habitantes, mais de uma dezena de periódicos diários em circulação e mais de trinta com periodicidade menor (cf. Levine, 1980). Jornais, revistas e livros eram publicados na cidade e o impresso se encontrava em todos os lugares. A taxa de analfabetismo era de 32,09\% entre as pessoas acima de 5 anos. Taxa alta quando se considera que estamos falando da terceira maior cidade do país na época; taxa baixa quando se compara com a média do Estado de Pernambuco: $74,34 \%$ de analfabetos nessa mesma faixa etária. ${ }^{26} \mathrm{Ha}-$

${ }^{25}$ Os livros desse autor eram largamente utilizados nas escolas da época, em todo o país. Publicados nas últimas décadas do século XIX, foram considerados inovadores naquele momento. Ver Pfromm Neto et al. (1974).

${ }^{26}$ Cf. Brasil, 1950. Em 1940, o índice brasileiro de analfabetismo para a população de mais de 15 anos era de 56,17\% (Romanelli, 1978). Em 1950, 28\% dos moradores das áreas urbanas e suburba- via uma grande movimentação em torno da produção cultural: teatros com apresentações de companhias nacionais e internacionais e cinemas espalhados pelas regiões centrais e pelos bairros.

Todo esse contexto possibilitava que, embora não de forma sistemática, os moradores da capital estivessem em permanente contato com o impresso, em seus contextos de uso. Roche (1996), em seu estudo sobre as práticas da escrita nas cidades francesas do século XVIII, revela que todas as grandes metrópoles regionais são produtoras e consumidoras de livros, de brochuras e de jornais. Nelas, a escrita representa algum papel mesmo para os que não a decifram. Uma série de práticas cotidianas relacionadas entre si passaram a ocupar um papel importante no incremento e na difusão do impresso.

Todas essas maneiras de utilizar os escritos, toda essa familiaridade com a circulação dos saberes sublinham as possibilidades de aculturação urbana. Com o impresso, esta adquire uma flexibilidade e uma capacidade pedagógica ainda maior. Entendamos claramente aqui que, para a maioria urbana, a relação com a escrita não implica necessária e unicamente o livro, e que a relação com o livro não coloca em questão apenas e de maneira uniforme o livro possuído. A leitura urbana passa por múltiplas formas em que a posse individual associa-se a manuseios coletivos e varia segundo os grupos e as ligações sociais. (p. 195-196).

Em Pernambuco do século XX, nas pequenas cidades do interior, por outro lado, as taxas de analfabetismo chegavam a $89,74 \%$, como em Bezerros, no Agreste, local de nascimento de um dos entrevistados. $\mathrm{Na}$ maioria dessas localidades, a circulação do impresso era muito restrita. Mesmo para aqueles que ingressavam em processos formais de escolarização era difícil atribuir sentido à aprendizagem da leitura e da escrita, na medida em que limitados (e, em alguns casos, quase inexistentes) eram os seus usos e as suas práticas. Nesses espaços, o impresso parecia estar mais presente nas celebrações religiosas. Os objetos de leitura e escrita nelas presentes pareciam comuns no cotidiano da épo-

nas com mais de 20 anos eram analfabetos, porcentagem que passava para 67,8\% nas áreas rurais. (Dias, 1993). 
ca: breviários, livros de missa, missais, livros de orações, livros de batismo, de casamento, de cerimônias para ingresso no seminário e de doações e bilhetes para venda nas festas de padroeiros foram objetos de leitura referidos, quase em sua totalidade, por Duarte (1988), em seu romance ambientado em uma cidade do Sertão. No livro, as referências às práticas de leitura praticamente se restringem a esses objetos. No caso dos folhetos, era mais comum que, naquele período, nas pequenas comunidades do interior, eles fossem mais ouvidos do que lidos:

Era a única diversão, nas bocas de noite aquele que sabia ler pr'aquela matutada que não sabia, ia tudo pra lá... Ele ia ler e mentir, né? E aquela matutada de boca aberta, escutando... Ninguém sabia ler, só ele que sabia, e ele era o campeão. Já aqui não, aqui todo mundo sabe, cada um lê pra si e acabou a história. [...] Lá era a coletividade e aqui é cada um pra si. Ninguém interessa. Tá lendo aqui, o outro tá fazendo uma toada ali... [...] O camarada sem concentração, assim é melhor [...] pegar os seus livrinho, levar pra sua casa, ficar em casa e ler à vontade. Quer dizer, bem individualista, lá era coletividade, né? Lá um lia pra todos e aqui cada um lia pra si. A diferença era só essa. (Zé Moreno)

A inserção no espaço urbano e a apropriação dos lugares públicos de convivência, entretanto, não se dava da mesma maneira para homens e mulheres. Elas pareciam permanecer, em larga medida, pelo menos no grupo social estudado, mais restritas ao espaço doméstico, ao privado. Até para comprar folhetos na feira ou no mercado, eram os homens os escolhidos para a tarefa. $\mathrm{Na}$ casa de um dos entrevistados, por exemplo, era ele quem, mesmo analfabeto, comprava os folhetos na feira. Ouvia atentamente a leitura do vendedor e, se a história fosse "bonita", comprava e levava para sua mulher. Alfabetizada, era ela quem lia as histórias, para ele e também para outros parentes e vizinhos que em sua casa se reuniam.

A pesquisa realizada por Ribeiro (1999), já citada, revela a permanência da influência da cultura urbana nos processos de aquisição das habilidades básicas e no desenvolvimento das competências em leitura e escrita. Rosemeire, uma das entrevistadas pela autora, afirma que aprendeu o que sabe lendo o nome dos ônibus e fo- lheando revistas. Outra entrevistada, Conceição, revela que aprendeu a ler "...passeando na rua com amigos que lhe mostravam os outdoors, explicavam o que anunciavam e indicavam as letras que formavam as palavras" (Ribeiro, 1999, p. 177).

\section{O papel do cinema}

No contexto urbano, algumas práticas se destacavam em relação às demais nos processos de letramento de determinadas parcelas da população. No período estudado, o cinema fazia parte do cotidiano da cidade, como uma das principais opções de lazer, para todas as camadas sociais. Presente em quase todas as entrevistas que realizei, nas memórias e romances analisados, aparece também como um objeto de leitura, referido como fundamental na formação de leitor. Zé Moreno destaca o cinema como seu "principal professor". Para ele, que na escola nem chegou a "completar a carta do ABC", as legendas do cinema o obrigavam a ser mais fluente na leitura. Em seu depoimento, é interessante observar como ele se coloca hoje diante do papel de leitor: autônomo, fluente, capaz de "comer com as próprias mãos". O contexto urbano, possibilitador do acesso a esses novos meios de lazer, ausentes no engenho de onde migrou, apresenta-se como estimulador de novos usos e práticas da leitura:

\section{Ah... Matuto não passa muito tempo na escola. Passa} mais na porta da escola. Aprendi pouco. Eu vi só a carta de ABC e talvez nem toda. Mas aí eu vim pra cidade e na cidade eu me desenrolei. O cinema foi o meu principal professor. Eu tinha que ler aquelas legendas, naquele tempo era inglês e vinha a legenda embaixo em português. ${ }^{27}[\ldots]$ E quem ensinou ler ligeiro foi o cinema, porque ou lia ligeiro ou não sabia a história, porque a legenda do cinema é (faz barulho e gesto significando rapidez). Não deixar passar nada. [...] Então, pra eu entender os segredos do filme, eu tinha que ler a legenda, aí

${ }^{27}$ Segundo Dias (1993), em que pese a grande produção de chanchadas brasileiras nas décadas de 1940 e 1950, a maior parte dos filmes exibidos no país eram estrangeiros, em grande parte, de origem americana. Em 1950, entraram no Brasil 1.798 filmes produzidos nos Estados Unidos, seguidos de longe pelos 168 filmes ingleses. Em 1953, foram 34 os filmes produzidos no Brasil. 
me aprofundei, esforcei e cheguei até onde estou. Graças a Deus hoje já sei comer com minhas mãos. [...] Juntar as duas letras e era a coisa mais difícil que eu achava, era juntar as sílabas e.. depois que eu aprendi isso, o cinema começou a me ensinar o resto, o jornal alguma besteira, o folheto o resto da coisa e o mundo, o professor mundo acabou de ensinar mais alguma coisa e... até que me serviu. (Zé Moreno)

Segundo Dias (1993), o cinema era, naquele momento no Brasil, uma grande diversão de massa: a maioria dos espectadores era formada pelas classes populares e médias urbanas. Em 1952, eram cerca de 180 milhões de espectadores e 2.411 salas exibidoras, para uma população urbana de 16 milhões e uma população total de cerca de 52 milhões de habitantes (cf. Anuário Estatístico do Brasil, de 1952 apud Dias, 1993). O Brasil colocava-se entre os dez primeiros países quanto ao número de cinemas e ao total de espectadores. Para a autora, o preço do ingresso também parecia facilitar o acesso do grande público aos cinemas: em 1952, o Brasil tinha o sétimo ingresso mais baixo da América Latina.

No entanto, como ocorria em relação aos processos de inserção no contexto urbano de modo geral, as mulheres, a julgar pela análise das entrevistas, autobiografias e romances analisados, pareciam freqüentar menos o cinema do que os homens. Algumas das entrevistadas, por exemplo, foram ao cinema pela primeira vez depois de casadas, mediadas, portanto, pela presença de um homem.

\section{O papel da "literatura popular"}

\section{A literatura de folhetos}

A maioria dos entrevistados destacou a leitura de folhetos como fundamental para desenvolver as competências de leitura. Diante da minha questão sobre pessoas que aprenderam a ler através dos folhetos, Zé Moreno não hesitou em colocar-se como um caso exemplar, embora, no conjunto de seu discurso, tenha atribuído sobretudo ao cinema o desenvolvimento de suas capacidades de leitura. Nesse trecho da entrevista, compara o prazer desfrutado na leitura de folhetos ao enfado provocado pelas lições escolares, conhecidas em sua curta experiência de escolarização:
Porque eu aprendi na escola... a carta de ABC num versa, versa? É só aqueles dizerzinhos, (como se estivesse recitando:) "é meu pai, eu vou ler [...] vou ler mais", (voltando a falar normalmente) essas coisinhas, né? Dali aprendi, aprendi a juntar as duas sílabas, as duas letras pra fazer a sílaba, depois nome, pronome, não sei o quê, não sei o quê, não sei o quê, e fui juntando e o cinema me imprensou mais, me ajudava a desenvolver. [...] E foi isso minha vida. Eu aprendi ler quase no folheto. $\mathrm{O}$ folheto foi meu professor. [...] Na escola só fazia aprender bobagem.

Zé Mariano, que nunca aprendeu a ler, tem uma história particularmente interessante. Filho de pai alfabetizado, de quem ouvia as leituras de folhetos quando era menino, ainda no interior da Paraíba, depois de adulto, continuou a ouvir folhetos, desta vez com o auxílio da mulher e do filho, também alfabetizados. Em seu depoimento, destaca o papel dos folhetos para desenvolver as capacidades de leitura: “...meu pai gostava de usar muito folheto. Dava aos meninos e dava pra dar a gente, né? Quem sabesse ler, pra decorar a leitura, pra desarnar a leitura, sabe? [...] Ele sabendo ler o folheto ele... ele pode... pode dizer de cor, pode dizer as coisa de cor". Zé Mariano repetiu o procedimento que seu pai fazia com ele próprio, em relação a seu filho:

De lá pra cá eu comprei pro meu menino, meu menino tava acanhado, num sabia soletrar uma letra, aí eu comprei pra ele os folheto, pra ele... pra ele saber, pra instruir, pra ele aprender, desarnar as letra e tudo. [...] Aí eu... eu entreguei a ele, comprei o folheto pra ele, aí ele pegou, de... de... desarnou a letra. Isso aí melhorou mais a leitura dele.

E continua: "Isso tudo é bom pra o menino que tá aprendendo ler, quando num sabe ler. Pra ver o menino [...], num sabe soletrar a letra, num sabe juntar uma letra, aí... o folheto explica, né? Ele lê aquele folheto, o folheto explica. Aí sai, sai, sai, aí vai... alguém vai desarnando". Mesmo quando se refere a esse aspecto propriamente "instrutivo" dos folhetos, Zé Mariano o relaciona com sua dimensão estética: Ler, lia desarnado mesmo. É bonita as palavras. 


\section{O utros tipos de literatura considerados "populares"}

Outros tipos de literatura, tradicionalmente classificadas como "populares", pareciam também contribuir para o processo de desenvolvimento das competências de leitura e da inserção gradativa de populações semiletradas no mundo da cultura escrita. No grupo de pessoas que entrevistei, três principais tipos de impressos foram citados como componentes de suas leituras: as histórias em quadrinhos, os romances policiais e os almanaques. Esses gêneros literários, a princípio dirigidos a um público popular, também circulavam na época junto a um público mais vasto, pertencente às camadas médias, como parece indicar a análise de outras fontes, como memórias e romances.

Um dos entrevistados afirmou que lia as histórias em quadrinhos quando ainda era criança, identificandoas como um tipo de literatura tipicamente infantil. Um outro sujeito também associou os quadrinhos aos livros infantis, afirmando que os "segredos e as figuras" das revistas foram, por muito tempo, objeto de sua leitura (Zé Moreno). O vendedor de cordéis, no ramo desde 1938, identificou os quadrinhos ao público consumidor de folhetos, afirmando, no entanto, que eram poucas as opções em torno desse tipo de literatura. As histórias em quadrinhos pareciam, assim, ser amplamente difundidas entre os segmentos populares. Como já foi referido, no entanto, a leitura dessas histórias parecia não estar restrita a determinada camada social, apesar de não ser identificada como gênero literário. ${ }^{28}$

Alguns leitores entrevistados liam também outro tipo de literatura classificada como popular: os romances policiais, com histórias de detetives ou "histórias de crime", como denominou um dos sujeitos. Zé Moreno afirma que, pouco a pouco, os folhetos foram dando lugar a esses livros, em sua trajetória como leitor:

${ }^{28}$ Para muitos autores, os anos 1930 e 1940 podem ser considerados a "época de ouro" dos quadrinhos, em todo o mundo. Segundo Paraíso (1996), que compartilha dessa afirmação, algumas das histórias mais difundidas mundialmente começaram a ser publicadas no Brasil em 1934, em um suplemento infantil do jornal A Nação, um dos principais jornais do Rio de Janeiro na época.
Passei pra ler aqueles livreto de detetive. Aquilo me interessa muito, embora comeu minha vista, a minha vista era boa, hoje tá meia cansada... mas ainda gosto de ler... pra matar o tempo. [...] É, eu comprava de dez, doze, aquelas tulha. Comprava, eu comprava uns cinco, digamos hoje, na banca, daqueles cinco eu lia mais trinta, porque eu ia trocando nas banca, trocando um pelo outro, um por outro, quando eu ia com um novo $[. .$.$] trocava por dois usados e assim ia...$

Os livros de detetive, à semelhança das histórias em quadrinhos, embora a princípio dirigidos a um público popular, também circulavam na época junto a um público mais vasto, pertencente às camadas médias, como demonstram as autobiografias e os romances analisados. Muitas vezes conhecidos como narrativas simplesmente capazes de prender a atenção do leitor, os romances policiais têm sido classificados, pela maioria dos críticos, como "subliteratura". Principalmente os daqueles autores que se tornaram mais populares, em sua maioria originários dos Estados Unidos, Inglaterra e França, foram, em especial ao longo do século XX, amplamente traduzidos e difundidos, muitas vezes em edições baratas e de bolso, por todo o mundo. $\mathrm{O}$ fascínio que exerceram entre esse amplo público consumidor pode ser demonstrado através da afirmativa de Zé Moreno: “...aqueles livreto que tinha pequeno com a história, sem nenhuma figura, só a história, que aquilo é que é importante, a gente quer saber é a história. Aquilo eu li muito, muito, passei muito tempo lendo aquilo, ainda hoje quando eu pego..." O universo dos romances policiais (ver, entre outros, Medeiros e Albuquerque, 1979), pode-se afirmar, não se distancia significativamente daquele de outros tipos de narrativa considerados populares, como os próprios folhetos de cordel: a estrutura das histórias segue esquemas mais ou menos constantes, em que se destaca a luta do bem contra o mal.

Outro tipo de objeto de leitura tradicionalmente classificado como popular ou "subliteratura" - o almanaque - também esteve presente na trajetória de leitores/ ouvintes entrevistados e de alguns memorialistas/romancistas. Os entrevistados e entrevistadas recordam-se de que os almanaques eram muito presentes no cotidiano da época, distribuídos, na maior parte das vezes, na farmácia, como um brinde (ver Casa Nova, 1996). Lem- 
bram-se, sobretudo, dos "signos", dos "negócio de lua, da sorte" e dos "dizeres" que traziam. De maneira similar às histórias em quadrinhos e romances policiais, os almanaques, embora não fossem considerados uma leitura "legítima", circulavam também entre as camadas médias da população.

Outros tipos de objetos impressos também faziam parte do universo de leituras/audições dos grupos de pessoas com que trabalhei, embora não de forma tão significativa. Entre eles, destacam-se as modinhas, folhinhas e livros de sorte. Alguns poucos liam também revistas. Mais uma vez, nesse caso, o pertencimento de gênero parece significativo: a única mulher que se revelou leitora de revistas afirmou que a elas teve acesso depois do casamento, através da mediação do marido. Quase todos os entrevistados, exceto um, afirmaram não ter o hábito de ler jornais. Os entrevistados não se referiram à leitura de nenhum livro pertencente aos consagrados cânones literários. No entanto, moravam principalmente no Recife, em um mesmo meio em que circulava uma variedade de obras literárias; onde eram publicados, divulgados e consumidos livros de autores locais, nacionais e estrangeiros.

Todos esses processos, como pôde ser observado, referiam-se, sobretudo, à aprendizagem e às práticas de leitura. Nada se sabe, se considerarmos certas definições e certos instrumentos utilizados para medir níveis de letramento sobre os conhecimentos que possuíam os sujeitos em relação à matemática, às ciências naturais e sociais. Mesmo em relação à leitura, por não ter sido o objetivo do estudo, não se têm elementos para medir níveis de compreensão de um texto, por exemplo. E pouco se sabe - já que não era o objetivo inicial da pesquisa sobre os processos de aquisição das habilidades básicas da escrita. Apenas um dos entrevistados se referiu ao ato de escrever, afirmando que ele era mais fácil do que ler porque “...escrever, você escreve qualquer garrancho, mas ler não, ler você precisa saber direito, precisa compreender" (Zé Moreno). Certamente, o entrevistado chama a atenção para o caráter de imprevisibilidade que caracteriza a leitura: não se pode prever o que se vai ler. A todo momento, pode-se deparar com uma semântica, uma sintaxe, um corpo de significados, enfim, uma enciclopédia (cf. Eco, 1986) que não é a do leitor. Quando se escreve, principalmente se pensarmos em textos simples, ao contrário, lida-se com um conjunto limitado, e conhecido pelo sujeito escritor, de palavras, de estruturas sintáticas, de sentidos. Não se pode escrever o que não se sabe. Apesar de serem poucas as referências feitas pelos entrevistados sobre a escrita, sabe-se, no entanto, que era comum, no universo em que estavam inseridos os sujeitos que entrevistei, a leitura e audição de cartas, bilhetes, telegramas e outros objetos que circulavam em suportes não impressos. A referência à escrita e ao envio de cartas é feita em todos os romances e memórias analisados, parecendo ser este o meio de comunicação à distância mais utilizado e a prática de escrita mais comum no período, entre todas as camadas da população. Foi também o desejo de escrever cartas para seus parentes no interior a principal motivação de Sebastião, sujeito entrevistado na pesquisa de Ribeiro (1999), para aprender a escrever.

\section{Consideraçõesfinais}

Gostaria de destacar algumas questões que considero importantes, a partir de dados da pesquisa que realizei, para a melhor compreensão do fenômeno do letramento ou alfabetismo no passado brasileiro.

Inicialmente, parece haver uma série de fatores que determinam ou influenciam os modos de inserção das pessoas no mundo letrado. Uma das constatações mais fortes do estudo revela que há diferenças significativas entre as práticas de leituras e também entre as relações dos leitores/ouvintes com os objetos de leitura, nos centros urbanos e nas pequenas cidades do interior e comunidades rurais. $\mathrm{O}$ pertencimento de gênero e as ocupações dos sujeitos também se revelaram fatores importantes na compreensão do processo de inserção das pessoas no mundo da cultura escrita.

Apesar de a aprendizagem inicial da leitura e da escrita ser considerada outro fator importante, níveis de escolarização nem sempre coincidem com níveis de letramento. A formação do leitor, assim, não está diretamente associado à escola nem a níveis de escolarização. Zé Moreno, leitor “fluente", capaz de reconhecer e definir signos da cultura letrada, como o prefácio e o índice de um livro, consumidor sôfrego de livros, capaz 
de fruir das leituras que faz, passou menos de um ano na escola. A sua trajetória como leitor, iniciada com folhetos ainda no engenho onde nasceu e morou até os 16 anos, intensificou-se com a experiência urbana: cinema, livros de detetive, histórias em quadrinhos e ainda os folhetos o tornaram um leitor incansável.

Creio que também vale a pena ressaltar que não se pode associar diretamente um objeto de leitura a uma camada social determinada, como já mostraram estudos realizados em outros países. As relações entre objetos de leitura e grupos sociais são muito mais complexas.

Considero importante destacar, ainda, a necessidade da realização de pesquisas, no campo da história da educação, que se debrucem sobre processos educativos que, com muita força, de maneira independente da escola, das políticas públicas e dos movimentos sociais organizados, contribuíram para a inserção de homens e mulheres em determinados mundos culturais.

Gostaria de realizar outras reflexões, que podem ser situadas mais do ponto de vista da compreensão da realidade e menos do ponto de vista das pesquisas acadêmicas. O tipo de pesquisa no qual se insere a que trouxe para este texto contribui, creio, ao buscar apreender as trajetórias de vida e de leitura dos sujeitos, para complexificar as visões correntes na sociedade a respeito do analfabeto ou semi-analfabeto. Vítima, digno de piedade, incapaz de elaborar articuladamente o pensamento e a fala, atrasado (já que associado às sociedades tradicionais e orais), imbecil: ${ }^{29} \mathrm{o}$ analfabeto ou semi-alfabetizado é, via de regra, visto como alguém que precisa, por diferentes motivos, da "ajuda" do alfabetizado (do intelectual, em particular), capaz de retirá-lo da situação em que se encontra.

Esses pressupostos acima explicitados vêm, de certa forma, norteando, ao longo da história, as políticas de combate ao analfabetismo, muitas das quais baseadas em campanhas (ver, entre outros, Soares, 1995). Hoje, esses pressupostos se consubstanciam, em grande medida, em projetos de grandes dimensões, em geral realizados em municípios com altos índices de analfabetismo,

${ }^{29}$ Ver estudo de Matencio (1995) a respeito das imagens do analfabeto veiculadas na mídia. e onde, via de regra, a escrita não desempenha papel significativo no cotidiano de seus habitantes, pressupõe (e depoimentos de intelectuais participantes do programa confirmam isso) a necessidade de "inventar" funções e usos sociais para a escrita, a fim de que o seu ensino adquira sentido. Por mais que seja criticado na literatura especializada, o mito do alfabetismo (Graff, 1984) parece basear essas afirmações: o papel dos professores universitários, em geral "convocados" de outras regiões, parece ser o de "salvadores" das populações que vivem nas "trevas do analfabetismo". ${ }^{30}$

Finalmente, creio que estudos como os descritos neste texto podem contribuir para se pensar na questão dos grandes instrumentos de medida do letramento que, muitas vezes baseados em uma lógica escolar supostamente universal, acabam ignorando as especificidades de cada uma das culturas (nacionais, regionais, locais) onde serão utilizados. ${ }^{31}$

ANA MARIA DE OLIVEIRA GALVÃO, doutora em Educação pela Universidade Federal de Minas Gerais, é professora de História da Educação no Centro de Educação da Universidade Federal de Pernambuco. Dedicando-se a estudos e pesquisas nas áreas de História da Educação e História da Leitura no Brasil, publicou Amansando meninos: uma leitura do cotidiano da escola a partir da obra de José Lins do Rego (1890-1920) (Editora da Universidade Federal da Paraíba, 1998), co-organizou "Leitura: práticas, impressos, letramentos (Editora Autêntica, 1999) e é também autora de capítulos de livros e artigos em periódicos. E-mail: anagalvao@nlink.com.br

\section{Fontes citadas: memórias e romances}

ALVES DA MOTA, (1987). Tempestade no porão. Rio de Janeiro: Cátedra.

BEZERRA, Gregório, (1980). Memórias. Primeira parte: 1900-1945. Rio de Janeiro: Civilização Brasileira.

${ }^{30}$ Há décadas, estudos realizados no campo da educação popular vêm criticando essa postura "salvacionista" característica de alguns programas.

${ }^{31}$ Para uma discussão sobre questões dessa natureza e sobre o papel da escola na "invenção" do iletrismo no caso francês, ver Chartier e Hébrard (1992) e Hébrard (1990). 
DUARTE, Ovídio, (1988). Pedra rosada. Recife: Edições do Autor.

FREIRE, Paulo, (1994). Cartas a Cristina. Rio de Janeiro: Paz e Terra.

FREYRE, Gilberto, (1975). Tempo morto e outros tempos: trechos de um diário de adolescência e primeira mocidade (1915-1930). Rio de Janeiro: José Olympio.

PARAÍSO, Rostand, (1996). Antes que o tempo apague (crônica dos anos 40 e 50). Recife: Comunicarte.

REGO, José Lins do, (1993). O moleque Ricardo. 19ed. Rio de Janeiro: José Olympio.

SETTE, Hilton, (1995). Estranha penitência: crônica romanceada de uma Olinda dos bons tempos nos anos vinte. Recife: Comunicarte.

VAREJÃO, Lucilo, (1992). De que morreu João Feital. Recife: Fundação de Cultura da Cidade do Recife.

\section{Referências bibliográficas}

ALVIM, Rosilene, (1997). A sedução da cidade: os operários camponeses e a fábrica dos Lundgren. Rio de Janeiro : Graphia.

BRASIL. Instituto Brasileiro de Geografia e Estatística, (1950). Recenseamento Geral do Brasil ( $1^{\circ}$ de setembro de 1940). Censos demográfico: população e habitação. Quadros de totais referentes ao Estado e de distribuição segundo os municípios. Quadros sinóticos por município. Série Regional, parte IX - Pernambuco, tomo 1. Rio de Janeiro : Serviço Gráfico do Instituto Brasileiro de Geografia e Estatística

CASA NOVA, Vera, (1996). Lições de almanaque. Belo Horizonte: Ed. da UFMG.

CHARTIER, Anne-Marie, HÉBRARD, Jean, (1992). Rôle de l'école dans la construction sociale de l'illesttrisme. In: BESSE, JeanMarie et al. (dir.). L'illettrisme’ en questions. Lyon : Presses Universitaires de Lyon.

DIAS, Rosângela de Oliveira, (1993). O mundo como chanchada: cinema e imaginário das classes populares da década de 50. Rio de Janeiro : Relume-Dumará.

ECO, Umberto, (1986). Lector in fabula. São Paulo : Perspectiva.

FRIJHOFF, Willem (dir.), (1996). Autodidaxies (XVIe-XIXe siècles). Histoire de l'Éducation, Paris, n.70.

GALVÃO, Ana Maria de Oliveira, (1994). Escola e cotidiano: uma história da educação a partir da obra de José Lins do Rego (18901920). Mestrado em Educação. Faculdade de Educação da Universidade Federal de Minas Gerais.

(1998). Amansando meninos: uma leitura do cotidiano da escola a partir da obra de José Lins do Rêgo (1890-1920). João Pessoa : Editora Universitária/UFPB.

(2000). Ler/ouvir folhetos de cordel em Pernambuco

(1930-1950). Doutoramento em Educação. Faculdade de Educação da Universidade Federal de Minas Gerais.

GRAFF, Harvey J., (1994). Os labirintos da alfabetização: reflexões sobre o passado e o presente da alfabetização. Porto Alegre : Artes Médicas.

HÉBRARD, Jean, (1996a). Alphabétisation et accès aux pratiques de la culture écrite en Vaunage à la fin du XIXe. siècle (étude de cas). In: La Vaunage au XIXe. siècle: approche économique, sociale et politique d'une communauté paysanne de la région nîmoise. Nimes : C. Lacour Éditeur.

(1996b). O autodidatismo exemplar: como JamereyDuval aprendeu a ler? In: CHARTIER, Roger (org.). Práticas da leitura. São Paulo : Estação Liberdade.

(1990). L'invention de l'illettrisme dans le pays alphabétisés: le cas de la France. In: PRIVAT, Jean-Marie, REUTER, Yves (dirs.). Lectures et médiations culturelles. Lyon: Presses Universitaires de Lyon.

, (s.d.). Le lecteur autodidacte. In: Le grand Atlas de la littérature. Paris : Encyclopaedia Universal.

KLEIMAN, Angela B. (org.), (1995). Os significados do letramento: uma nova perspectiva sobre a prática social da escrita. Campinas: Mercado de Letras.

LEVINE, Robert, (1980). A velha usina: Pernambuco na federação brasileira (1889-1937). Rio de Janeiro : Paz e Terra.

MAGALHÃES, Justino, (1999). Alfabetização e História: tendências e perspectivas. In: BATISTA, Antônio Augusto Gomes, GALVÃO, Ana Maria de Oliveira (orgs.). Leitura: práticas, impressos, letramentos. Belo Horizonte : Autêntica.

MATENCIO, Maria de Lourdes, (1995). Analfabetismo na mídia. In: KLEIMAN, Angela B. (org.). Os significados do letramento: uma nova perspectiva sobre a prática social da escrita. Campinas: Mercado de Letras, p. 239-266.

MAXADO, Franklin, (1984). O cordel televisivo: futuro, presente e passado na literatura de cordel. Rio de Janeiro: CODECRI. 
MEDEIROS E ALBUQUERQUE, Paulo, (1979). O mundo emocionante do romance policial. Rio de Janeiro : Francisco Alves.

MEYER, Marlyse, (1980). Autores de cordel. São Paulo: Abril Cultural.

PFROMM NETO, Samuel, ROSAMILHA, Nelson, DIB, Claúdio Zaki, (1974). O livro na educação. Rio de Janeiro : Primor/ INL.

RATTO, Ivani, (1995). Ação política: fator de constituição do letramento do analfabeto adulto. In: KLEIMAN, Angela B. (org.). Os significados do letramento: uma nova perspectiva sobre a prática social da escrita. Campinas : Mercado de Letras.

REGO, José Lins do, (1977). Doidinho. 16ed. Rio de Janeiro : José Olympio.

RIBEIRO, Vera Masagão, (1999). Alfabetismo e atitudes: pesquisa com jovens e adultos. Campinas : Papirus.
ROCHE, Daniel, (1996). As práticas da escrita nas cidades francesas do século XVIII. In: CHARTIER, Roger (org.). Práticas da leitura. São Paulo : Estação Liberdade.

ROMANELLI, Otaíza de Oliveira, (1978). História da educação no Brasil (1930/1973). Petrópolis : Vozes.

SOARES, Leôncio José Gomes, (1995). Educação de adultos em Minas Gerais: continuidades e rupturas. Tese de doutorado. Faculdade de Educação da Universidade de São Paulo.

SOARES, Magda B, (1995). Língua escrita, sociedade e cultura: relações, dimensões e perspectivas. Revista Brasileira de Educação, Belo Horizonte, n.0, p. 5-16.

, (1998). Letramento: um tema em três gêneros. Belo Horizonte : Autêntica.

TERRA, Ruth Brito Lemos, (1983). Memória de luta: primórdios da literatura de folhetos do Nordeste (1893-1930). São Paulo : Global. 